\title{
Mediastinal parathyroidectomy with the da Vinci robot: Presentation of a new technique
}

\author{
J. Bodner, MD, ${ }^{a}$ C. Profanter, MD, ${ }^{a}$ R. Prommegger, MD, Prof, ${ }^{a}$ A. Greiner, MD, \\ R. Margreiter, MD, Prof, ${ }^{a}$ and T. Schmid, MD, Prof, ${ }^{a}$ Innsbruck, Austria
}

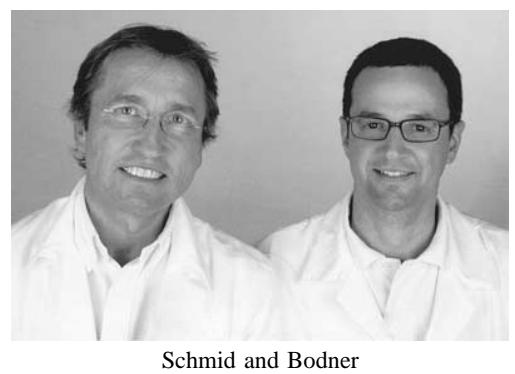

L ocalization and removal of ectopic glands is one of the major problems in parathyroid surgery. ${ }^{1}$ More recently, minimally invasive techniques have been under evaluation for such indications. ${ }^{2,3}$ The introduction of robotic surgical systems has revolutionized the field of minimally invasive surgery by improving vision and motion control. ${ }^{4}$ We here report on the first thoracoscopic mediastinal parathyroidectomy performed with an operating robot.

\section{Clinical Summary}

In a 57-year-old female patient with confirmed primary hyperparathyroidism, computed tomographic 2-methoxy isobutyl isonitrile (MIBI) image fusion localized an ectopic parathyroid in the aortopulmonary window (Figure 1). Informed consent was obtained from the patient, and the operation was performed totally thoracoscopically with the da Vinci robotic system (Surgical Intuitive, Inc, Mountain View, Calif).

The da Vinci robot consists of a master console, where the surgeon handles telemanipulators and optical controls with 3-dimensional vision, and the surgical arm cart, a manipulator unit with two instrument arms and a central arm to guide the twochannel endoscope. The surgeon's movement of the handles is transmitted to the tips of the robotic instruments. The main technologic advantage of this system is that it provides realistic 3-dimensional imaging, motion scaling, and tremor filtration. Thus it allows more precise and accurate endoscopic surgery. ${ }^{4}$

The patient was placed in a right lateral decubitus position with left single-lung ventilation (Figure 2). A 10-mm port for the robotic endoscope was positioned in the 6th intercostal space in the anterior axillary line, and two $8-\mathrm{mm}$ robotic operating ports were placed in the 4th intercostal space, a handbreadth right and left of the first incision. An accessory port was placed in the medioclavicular line through the sixth intercostal space, through which a

From the Departments of General and Transplant Surgery a and Vascular

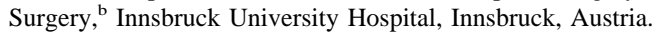

Received for publication Nov 17, 2003; revisions received Dec 3, 2003; accepted for publication Dec 30, 2003.

Address for reprints: Thomas Schmid, MD, Professor of Surgery, Department of General and Transplant Surgery, Innsbruck University Hospital, Anichstrasse 35, A-6020 Innsbruck, Austria (E-mail: thomas.schmid @ uibk.ac.at).

J Thorac Cardiovasc Surg 2004;127:1831-2

$0022-5223 / \$ 30.00$

Copyright $\odot 2004$ by The American Association for Thoracic Surgery

doi:10.1016/j.jtcvs.2003.12.036

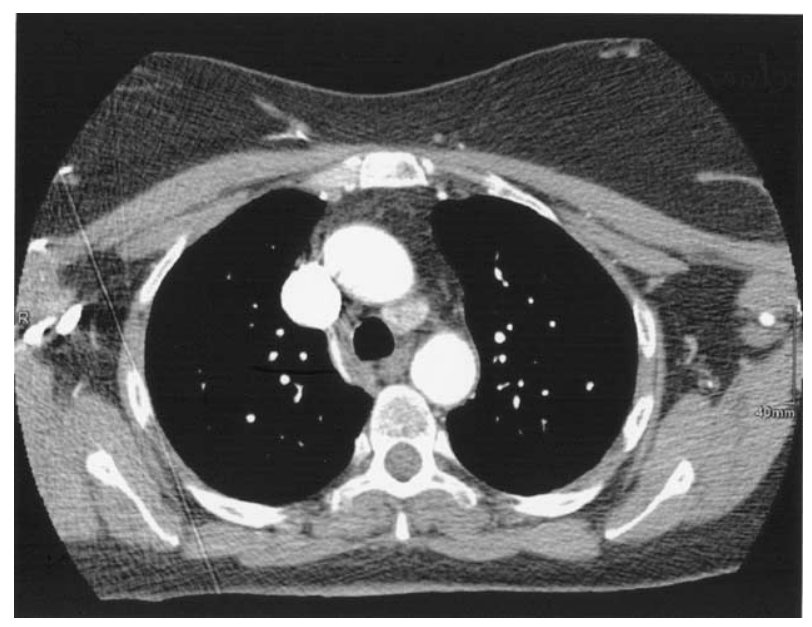

Figure 1. Computed tomographic image showing ectopic parathyroid in aortopulmonary window, adjacent to trachea.

flexible retractor (US Surgical, Norwalk, Conn) was inserted to hold the lung away. A second accessory port through the posterior axillary line of the 6th intercostal space was provided for eventual suction. Resection of the adenoma was performed exclusively by the surgeon at the console. Preparation started with incision of the parietal pleura covering the aortopulmonary window. The left vagal and recurrent laryngeal nerves were identified. Dissection proceeded beyond the small curvature of the aortic arch towards the trachea. The adenoma was identified adjacent to the trachea between the common trunk of the pulmonary artery and the aorta. Robotic manipulation was performed mainly bluntly with partial use of electrocautery, and care was taken not to rupture the adenoma's capsule (Figure 3). The vascular pedicle was controlled with clips. Minor bleeding from adjacent connective tissue was controlled by compression. Once the adenoma had been freed, it was removed with an Endobag system (Auto Suture, Division of US Surgical). At the end of the operation, a chest tube was placed.

\section{Results}

The overall operative time was 130 minutes, with 100 minutes for the robotic act alone. Blood loss was minimal, and there were no surgical complications. The patient showed a distinct hoarseness after the operation, which was caused by reduced activity of the left recurrent laryngeal nerve. The chest tube was removed on postoperative day 2 , and the patient was discharged on day 4 . The $1.4 \times 1.0 \times 1.0-\mathrm{cm}, 1.5-\mathrm{g}$ specimen was histopathologically 


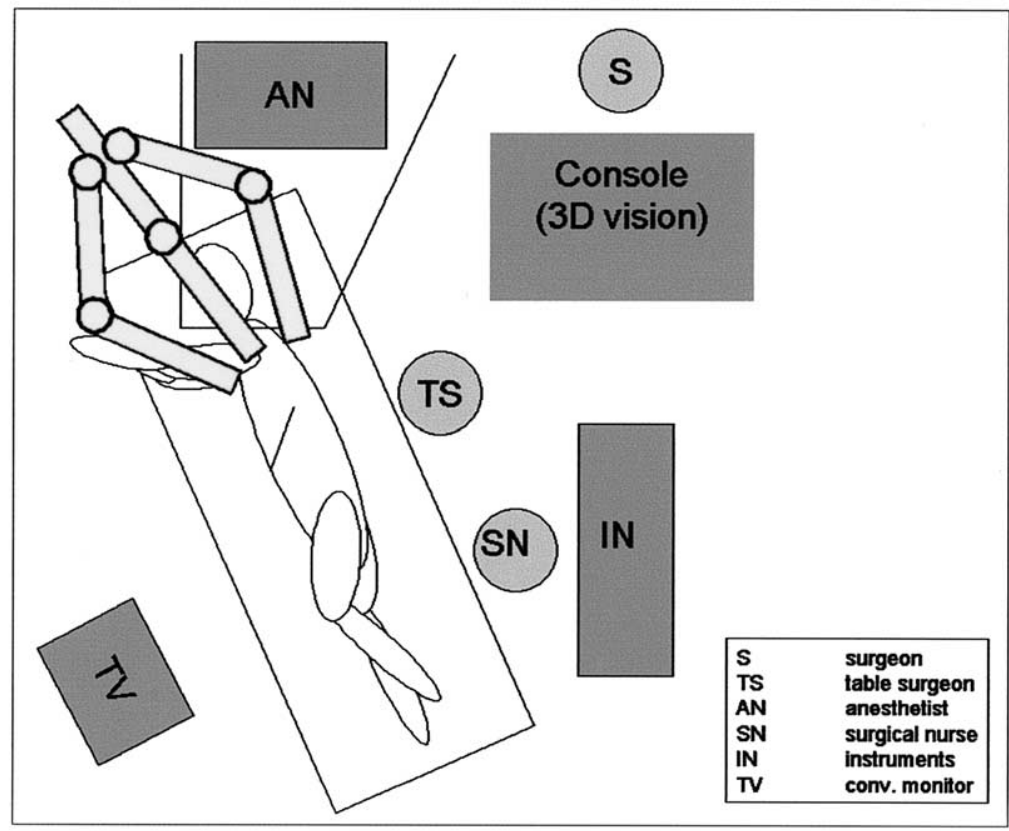

Figure 2. Schematic illustration of adjustment in operating room for ectopic parathyroidectomy with da Vinci robot.

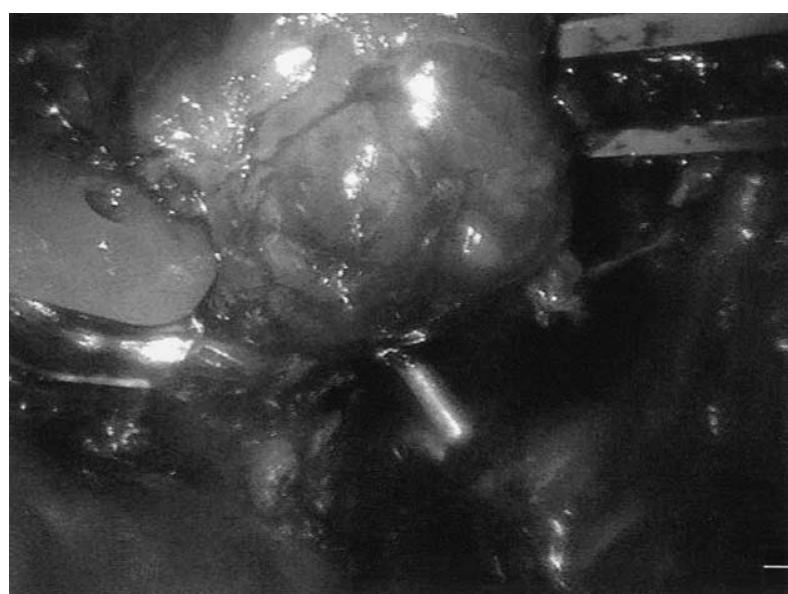

Figure 3. Adenoma $(1.5 \mathrm{~cm})$ was dissected with da Vinci robot, mainly bluntly with partial use of electrocautery.

confirmed as a parathyroid adenoma. Six months after the operation, the patient is clinically free of symptoms. Calcium and phosphate blood levels are normal, and her hoarseness has disappeared completely.

\section{Discussion}

About $20 \%$ of abnormal parathyroid glands are ectopic. ${ }^{1}$ In $1 \%$ to $2 \%$ of cases, the adenoma is located in the lower mediastinum, inaccessible through a cervical approach. ${ }^{5}$ Such ectopic parathyroids have been resected through a sternotomy or thoracotomy. ${ }^{5}$ To reduce the harm of an open operation, video-assisted thoracoscopic surgery has been explored for such purposes during the last
10 years. $^{2,3}$ Recently operating robots have been developed to overcome the drawbacks of video-assisted thoracoscopic surgery, such as impaired dexterity and vision control. The high-quality 3-dimensional camera image allowed easy localization of the tumor by the operating surgeon at the console, whereas the surgeon at the table side found it difficult to identify the lesion on the conventional monitor. The stable operation field and the precise movements of the tips of the instruments were extremely beneficial for operating in a tiny and remote area.

The resection of a parathyroid from the aortopulmonary window was thus proved to be an ideal case for the robot. The robotic procedure was found to be more accurate and safe than conventional video-assisted thoracoscopic surgery.

We thank emeritus Professor Ernst Bodner, MD, for his vision and endeavors that enabled the acquisition of the da Vinci robot for the Department of Surgery, Innsbruck University Hospital, Innsbruck, Austria.

\section{References}

1. Kaplan EL, Yashiro T, Salti G. Primary hyperparathyroidism in the 1990s. Choice of surgical procedures for this disease. Ann Surg. 1992; 215:300-17.

2. Kao CL, Chou FF, Chang JP. Minimal invasive surgery for resection of parathyroid tumor in the aortopulmonary window. J Cardiovasc Surg (Torino). 2003;44:139-40.

3. Kido T, Hazama K, Inoue Y, Tanaka Y, Takao T. Resection of anterior mediastinal masses through an infrasternal approach. Ann Thorac Surg. 1999;67:263-5.

4. Schmid T. Robotic surgery. Eur Surg. 2002;34:155-7.

5. Prinz RA, Lonchyna V, Carnaille B, Wurtz A, Proye C. Thoracoscopic excision of enlarged mediastinal parathyroid glands. Surgery. 1994;116: 999-1005. 